\title{
Analisis Sistem Pembayaran SPP Dengan Metode Pemberian Report Secara Berkala
}

\author{
Yonata Laia*, Erick, Vincent Leonardy, Meliany S. Sumantri
}

*Program studi Sistem Informasi, Fakultas Teknologi dan Ilmu Komputer, Universitas Prima indonesia

**Program studi Sistem Informasi, Fakultas Teknologi dan Ilmu Komputer, Universitas Prima indonesia

\begin{tabular}{ll}
\hline Artikel Info & Abstrak \\
Article history: & Penggunaan sistem dalam penginputan data seperti dalam sistem pelayan pembayaran \\
Received Jun $15^{\text {th }}, 2021$ & spp sudah banyak digunakan di swalayan, sekolah dan beberapa perusahaan yang lain \\
Revised Juli $29^{\text {th }}, 2021$ & juga. Namun samapai sekarang belum ada yang menggukan aplikasi yang dapat \\
Accepted Juli $29^{\text {th }}, 2021$ & $\begin{array}{l}\text { menirimkan lapaoran secara berkala kepada orang tua murid. Applikasi ini akan } \\
\text { menciptakan sebuah sistem yang dapat memberikan laporan secara berkala kepada orang } \\
\text { tua siswa. Berdasarkan masalah diatas peneliti akan melakukan peneltian pasa sekolah }\end{array}$ \\
Keyword & yayasan perguruan rakyat pancurbatu kabupaten deliserdang provinsi sumatera utara. \\
analisis & $\begin{array}{l}\text { Hasil dari aplikasi ini dapat membantu proses pekerjaa kasir yang melayani pembayar } \\
\text { Pembayar Spp }\end{array}$ \\
spp pada sekolah rakyat pancur batu. Dimana melayani 1 orang bisa memakan waktu 30 \\
menort & $\begin{array}{l}\text { menit perorang dengan adanya sistem ini sudah lebih cepat diketahui dari waktu } \\
\text { Sekolah }\end{array}$ \\
\hline
\end{tabular}

Corresponding Author:

Nama: Yonata Laia

Sistem Informasi

Universitas Prima Indonesia

*yonatalaia88@gmail.com

\section{PENDAHULUAN}

Seperti kita ketehui saat ini dimana-mana sudah banyak menggunakan sebuah sistem yang berbasis aplikasi off line maupun online yang dapat membantu pekerja manusia dalam penginputan data-data yang di perlukan seperti di perusahaan menginputan data pegawai, data barang, disekolah menginput data siswa, data spp. Disekolah yayasan perguruan rakyat pancurbatu masih menggunakan sistem secara manual sehingga kasir yang betugas dalam pembayarn spp sering kewalahan ketika orang tua yang melakukan pembayaran ketika sudah waktu mau uts dan uas, pengambilan raport maka semua orang akan segera beramai-ramai datang kekasir unutk memlunasi semua administrasi siswa/I yang bersangkutan.

Sistem adalah salah satu objek yang saling berhubungan yang sudah disusun dalam sebuah modul dan didalam sistem terdapat input, proses, hasil [1]. Sistem memiliki subsistem yang dapat bekerja secara bersamaan sesuai dengan item yanga kan kita gunakan[2]. Informasi adalah hasil yang sudah dioalah menjadi sebuah datang yang dapat dimengeri oleh manusia atau mengguna [3]. Sistem informasi memili kelebihan seperti memanipulasi, menyimpan, mendistrbusikan data yang yang sudah di input [4].

Sesuai dengan penjelasan diatas makan solusi dalam memperbaiki sistem pembayaran spp yang ada pada sekolah yayasan perguruan rakyat pancurbatu perlua dibuat sebuah sistem yang diolah melalui komputer agar lebih memudahkan pekerjaan dari pegawai yang bersangkutan.

Sistem yang akan di buat adalah sistem yang dapat memberikan laporan yang lebih lengkap seperti data siswa yang belum mbayar dan yang sudah membayar spp, laporan perpriode. Hasil dari penelitian ini diharapkan dapat berjalan dengan baik juga dapat membatu pihak pegawai yang melayani pembayaran spp. Aplikasi ini dapat di proses dikomputer mana saja asal ada sistem operasi windows 2010.

\section{METODE PENELITIAN}

Agar penelitian ini dapat dilakukan dengan baik maka peneltian ini pelu adanya sebuah kerangka penelitin yang terstruktur. Kerangkan penelitian adalah step yang akan di lakukan dalam penyelesaian permasalahan seperti yang di jelaskan pada latar belakang penneltian ini kerangka keja penelitian ini dapat dilihat pada gambar 1. 


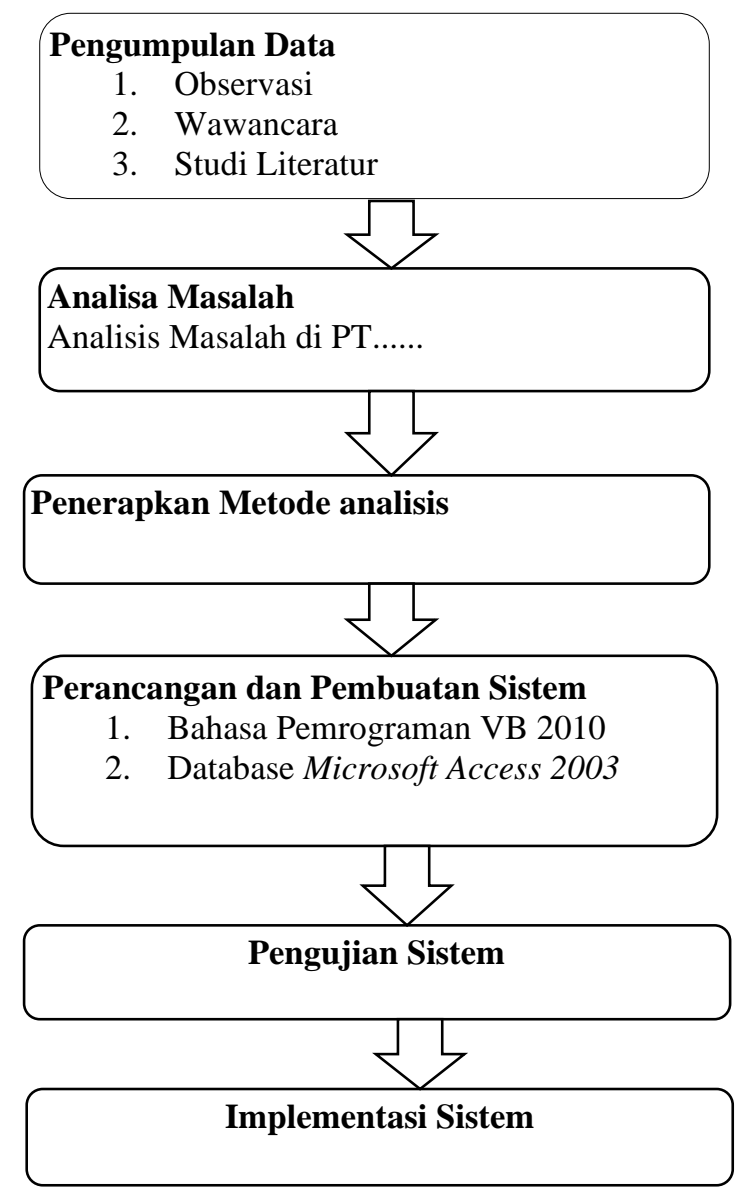

Gambar 1. Kerangka Kerja Penelitian

Keterangan:

1) Metode observasi

Metode observasi digunakan untuk mengetahui dan mengamati secara langsung objek yang diteliti dan juga melakukan proses pengumpulan data-data Kelurahan untuk pembayaran spp pada yayasan perguruan rakyat pancurbatu.

2) Metode wawancara

Pengumpulan data dengan tanya jawab kepada pihak sekolah.

3) Metode literatur

Studi literatur yang dilakukan adalah Teknik pengumpulan datan dengan cara membaca artikel, buku selanjutnya akan membandingkan hasil yang di peroleh dari artikel-artikel yang sudah di jadikan sebagai acuan dalam penelitianin seperti buku, jurnal.

3. ANALISA DAN HASIL

a. Form tampilan dibawah ini adalah tampilan penginputna data-data siswa sekolah swasta rakyat pancur batu yang terdiri dari unit SMP, SMA, SMA. 


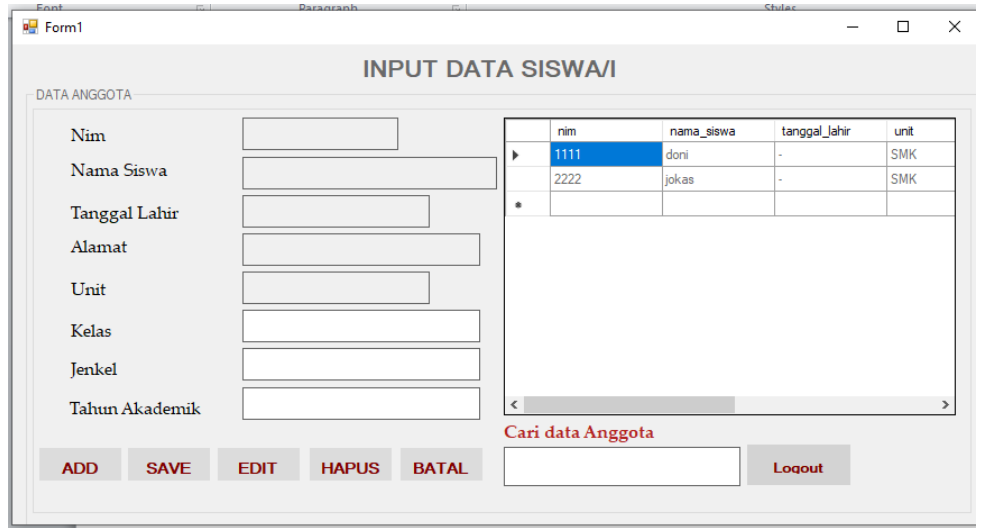

Gambar 2 Form Penginputan Data Siswa/I

b. Form Pembayaran

Pada tampilan form dibawah ini menampilakn proses pembayaran spp pada yayasan pergruan rakyat pancru batu deli serdang. Diman teridiri dari objek nis, nama, unit, kelas, tahun ajaran, spp, osis, pramuka. Lalu disini memiki sebuah tabel sementara yang berfungsi sebgai penampung data yang akan melakukan pembayaran. Setelah selesai atau sudah siap yang akan dibayar maka masuk kedalam tabel pembyaran.

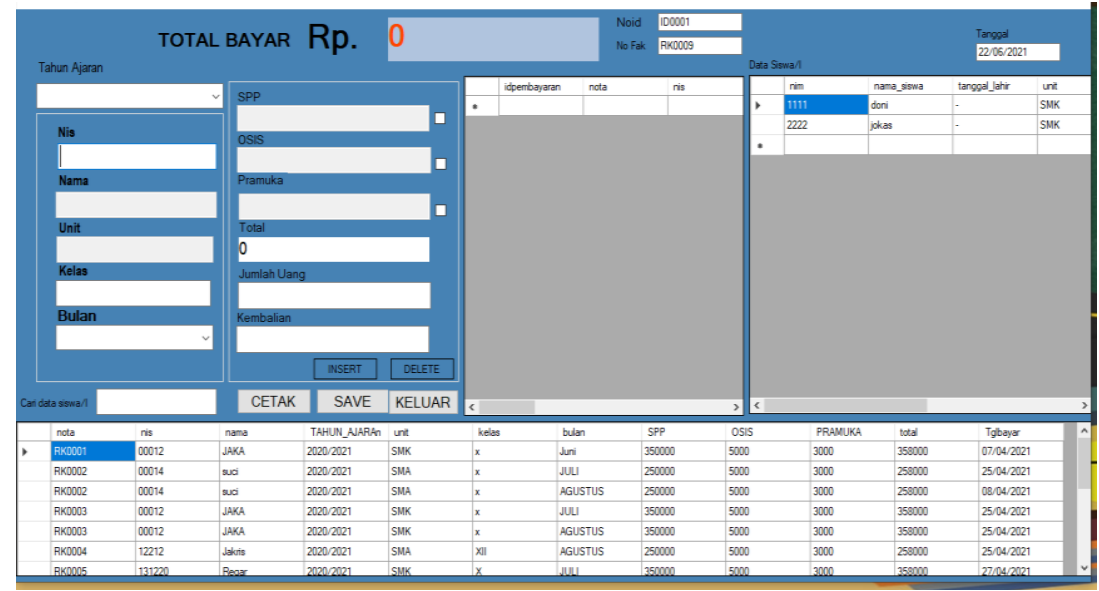

Gambar 3. Form Pembayaran spp

c. Tampilan cetak Slip Pembayaran

Pada tampilan dibawah ini adalah laporan slip pembayaran yang akan menampikan data-data siswa yang sudah melakukan pembayaran perorangan seperti yng terlihat pada gmbar 4 dibawah ini.

\begin{tabular}{|c|c|c|c|c|c|c|c|}
\hline \multicolumn{3}{|c|}{ 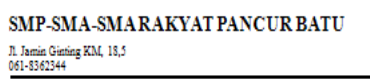 } & & \multicolumn{4}{|c|}{ 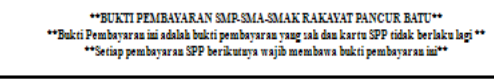 } \\
\hline $\begin{array}{l}\text { Nis } \\
\text { Nama } \\
\text { Kelas }\end{array}$ & $\begin{array}{l}\text { MIIfl } \\
\text { dori } \\
x\end{array}$ & & & & Nota : & RKo0008 & $22 / 06 / 2021$ \\
\hline \multicolumn{8}{|c|}{ Dengan Rincihan Sebagai Berikut: } \\
\hline $\mathrm{N}_{0}$ & Bulan & Tahun Ajaran & SPP & OSIS & Pramuka & Total & Tglbayar \\
\hline 1 & JULI & $2020 / 2021$ & 250000 & 5000 & 3000 & $\operatorname{Rp} 258.000$ & 26-Mei-2021 \\
\hline 2 & AGUSTUS & $2020 / 2021$ & 250000 & 5000 & 3000 & $\mathrm{Rp} 258.000$ & 26-Mei-2021 \\
\hline 3 & SEPTEMBER & $2020 / 2021$ & 250000 & 5000 & 3000 & Rp 258.000 & 26-Mei-2021 \\
\hline 4 & DESEMBER & $2020 / 2021$ & 250000 & 5000 & 3000 & $\mathrm{Rp} 258.000$ & 26-Mei-2021 \\
\hline \multicolumn{8}{|c|}{ Pancur Batu, 2206/2021 } \\
\hline & & & & \multicolumn{2}{|r|}{ Total Pembayaran } & \multicolumn{2}{|c|}{ Rp $1.032 .000,00$} \\
\hline
\end{tabular}

Gambar 4 Laporan slip Pembayaran 
d. Tampilan data perpriode

Tampilan data dibawah ini dalah laporan slip pembayaran berdasarkan mingguan, perhari, perbulan atau sesuai tang yang di inginkan.

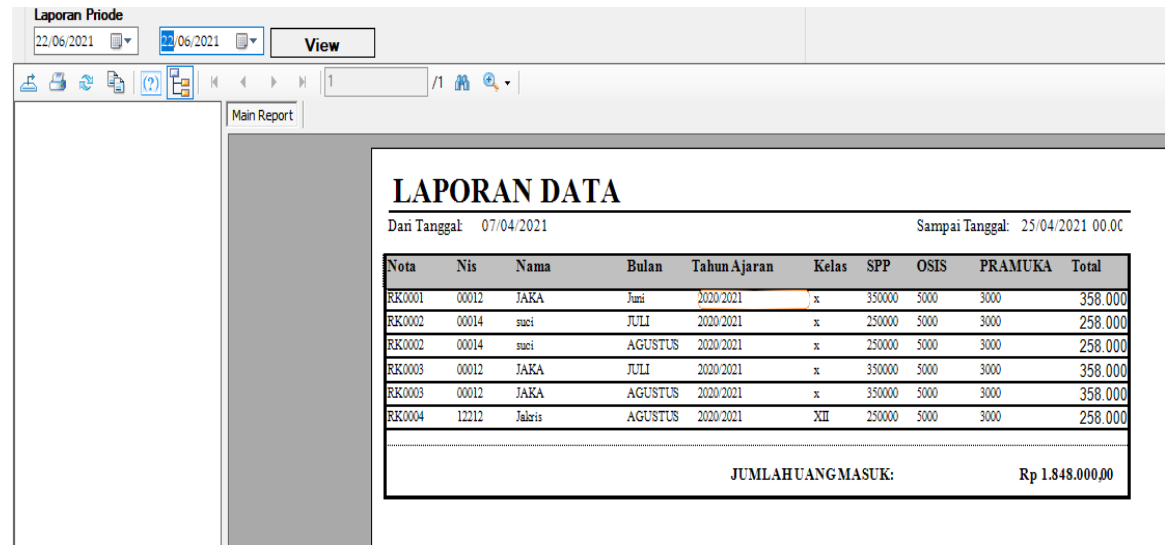

Gambar 5. Laporan Perpriode

e. Laporan uang masuk dan keluar

Pada tapilan dibawah ini adalah laporan uang masuk dan keluar dapat di input juga dalam sistem ini agar admin dapat memberikan laporan kepada yayasan apa saja uang yang sudah keluar dan masuk agar lebih mudah dalam melakukan pengecekkan setiap dibutukan oleh yayasan.

\section{LAPORAN UANG MASUK}

22/06/2021

\begin{tabular}{|llc|}
\hline Tanggal & Keterangan & Penerima \\
\hline $04 / 27 / 2021$ & PEMBAYARAN LAMPU & 30000 \\
$04 / 27 / 2021$ & Beli Gembok & 15000
\end{tabular}

Gambar 6 laporan uang masuk dan Keluar

\section{KESIMPULAN}

Sesuai dengan latar belakang dari penelitian ini adalah menciptakan sebuah sistem yang dapat memberikan solusi dalam pelayanan pembayaran spp. Pada penelitian ini akan melakuakn proses data yang masih aktif dan juga yang sudah tamat jika masih ada sangkutan administrasi belum selesai. Aplikasi ini dapat meminimalisir waktu yang digunakan dalam pelayanan dimana sebelimnya memakai waktu sampai 30 menit persiswa, dengan adanya aplikasi ini hanya memakai waktu 1 menit setiap siswa dalam satu jam dapat melayani pemabyaran kurang lebih 60 orang. 


\section{REFERENSI}

[1] A. Ashari, "Sistem InformasiPembayaran Sumbangan Pembinaan Pendidikan (SPP) pada Sekolah Menengah Atas Negeri 2 Pacitan," Indones. J.Netw. Secur., vol. 3, no. 3, pp. 65-70, 2014.

[2] S. Mulyani, Metode Analisis dan Perancangan Sistem. 2016.

[3] R. Pamungkas, "Perancangan Sistem Informasi Pembayaran Administrasi SMK Negeri 1 Jiwan," Intensif, vol. 1, no. 2, p. 129, 2017, doi: 10.29407/intensif.v1i2.799.

[4] I. K. Raharjana, Pengembangan Sistem Informasi Menggunakan Metodologi Agile. Yogyakarta, 2017.

[5] A. Rochman, A. Sidik, and N. Nazahah, "Perancangan Sistem Informasi Administrasi Pembayaran SPP Siswa Berbasis Web di SMK Al -Amanah,"vol. 8, no. 1, 2018.

[6] N. Wiliani and S. Zambi, "RANCANG BANGUNAPLIKASI KASIR TIKET NONTON BOLA BARENG PADA X KASIR DI SUATU LOKASI X DENGAN VISUAL BASIC 2010 DAN MYSQL,” vol. 1, no. 1, pp. 287-295, 2017, doi:10.1016/j.sbspro.2015.04.758.

[7] M. Mustakim and K. Krisnawati, "Analisis Dan Perancangan Sistem Informasi Akuntansi Laporan Keuangan Pada Pusat Perusahaan Distributor Air Mineral Mq Jernih Yogyakarta,” Data Manaj. dan Teknol. Inf., vol. 15, no. 3, p. 26, 2014.

[8] F. Annisa, F. I. Terapan, andU. Telkom, "Aplikasi Pengelolaan Dan Peminjaman Ruangan Di FakultasIlmu Terapan, Universitas Telkom Room Management and Booking Application At Schoolof Applied Science, Telkom University," vol. 3, no. 2, pp.600-605, 2017.

[9] Y. Heriyanto, "PerancanganSistem Informasi Rental Mobil Berbasis Web Pada PT.APM Rent Car,"J. Intra-Tech, vol. 2, no. 2, pp. 64-77, 2018.

[10] Suendri, "Implementasi Diagram UML (Unified Modelling Language) Pada Perancangan Sistem Informasi Remunerasi Dosen Dengan Database Oracle(Studi Kasus: UIN Sumatera Utara Medan),” J. Ilmu Komput. dan Inform., vol. 3, no. 1, pp. 1-9, 2018.

[11] M. Y. Putra and J. Shadiq, "Sistem Informasi Penerimaan Siswa Baru pada SMK Bekasi Berbasis Website," vol.7, no. 1, pp. 43-52, 2020.

[12] J. F. Andry, "PENGEMBANGAN APLIKASI BACKUP DAN RESTORE SECARA AUTOMATIS MENGGUNAKAN SDLC UNTUK MENCEGAH BENCANA,”pp. 29-38, 2015.

[13] A. A. Murtopo and D. C. Angesti, "Sistem Informasi Pelayanan Tagihan Rekening Dan Pengaduan Pelanggan Berbasis Sms Gateway Di PdamKota Tegal,” Simetris J. Tek. Mesin, Elektro dan Ilmu Komput., vol. 8, no. 2, p. 457, 2017, doi: 10.24176/simet.v8i2.1230.

[14] A. Hendini, "PEMODELAN UML SISTEM INFORMASI MONITORING PENJUALAN DAN STOK BARANG (STUDI KASUS: DISTRO ZHEZHA PONTIANAK)," CropSci., vol. iv, no. 2, pp. 108-111, 2016, doi: 10.2135/cropsci1983.0011183x002300020002x.

[15] R. Yanto, Manajemen Basis Data Menggunakan MySQL. 2016. 